Since the introduction of the College 'accreditation' (now 'approval') exercise, each district service provides a considerable amount of postgraduate training. Case conferences and journal clubs are now standard. Study leave is encouraged and the number of academic meetings organised by the Divisions and the various parts of the College have proliferated. Clinical skills are now more often taught in the trainee's base hospital in what is now a more open and questioning climate. Given all this, do trainees still require a day release course?

It is still probably true that basic sciences are more available at the Regional Centre. Neuroanatomy, pathology, neurophysiology, neuropharmocology, ethology, to name but a few subjects which are relevant, are usually not available outside the teaching centre. The basic sciences used to be concentrated in the first year course. Now the new examination requires more to do with the clinical interview and basic phenomenology, and basic sciences are required in the Part II. Should we still concentrate the basic sciences in the first year on the assumption that they still form the basis of psychiatry or spread them throughout the course?

The Southampton course used to assume that basic clinical skills were taught at the base hospital. However, the new Part I has brought an increased demand for these to be taught on the first year course. How can skills training be incorporated without more didactic parts of the course being dropped?

Over the last two years we have radically altered the MRCPsych course and are now incorporating a research element as a course within the Part II course. We get feedback from our trainees and we can find out examination results (sometimes with difficulty). Is this information good enough or should our courses be judged by some other criterion? Certainly approval teams seem only to check whether a course exists or not prior to giving their approval or not. The approval teams do not have the time or the remit to look critically at individual courses.

My feeling is that the College should now take a closer interest in MRCPsych courses. Their funding will inevitably be questioned in the near future. Are they still needed as is implied on Approval team visits when approval may depend on their existence? Perhaps the Dean should encourage more interest in this rather neglected aspect of training. Some central collection of information on existing courses might form the basis for a meeting of course organisers to share ideas about the future of these courses.

University Department of Psychiatry

Peter NotT

Royal South Hants Hospital

Southampton SO9 4PE
DEAR SIRS

Dr Nott's letter is timely and well taken. The College should be looking at MRCPsych courses once again although it is certainly not the intention to jeopardise their jealously preserved independence. The Chief Examiner recently carried out a survey of MRCPsych courses and the results of this will be made known at the next meeting of the Education Committee.

There is still a need for day-release courses in psychiatry as the undergraduate medical curriculum still gives very much less background for postgraduate trainees in psychiatry than, for example, in general medicine. Medical undergraduate teaching in psychology and sociology is still very much less intensive than anatomy, physiology or pathology; the clerkship in psychiatry is much shorter than either that for medicine or surgery. This means that trainees coming into psychiatry have less theoretical background in their specialty than their colleagues and contemporaries in other medical specialties; it is important that they obtain this background, both for building their subsequent psychiatric knowledge and for communicating with other professionals in the mental health services.

Ideally, teaching of the basic sciences should now be spread throughout the MRCPsych course. It may be difficult to achieve this but it is more in line with the current aim of making basic sciences more relevant to clinical experience.

It is still the intention that basic clinical skills should be taught at the base hospital. Approval visits to training schemes enquire about the training in clinical skills. More theoretical aspects of training in psychiatry are of greater relevance to MRCPsych courses.

I would agree that there is a need for a meeting of course organisers. One of the matters for discussion would be the criteria for success of an MRCPsych course. I am grateful to Dr Nott for raising this important issue.

Professor ANDRew Sims Dean

\section{Auditing of audit}

\section{DEAR SIRS}

The Royal College of Psychiatrists Working Party on Medical Audit (1989) recommends that "every consultant should be allowed to devote one session a week to audit". This is substantially more than the one session a month which has been recommended elsewhere (Health Service Journal, 1988).

If we assume that a consultant is paid between $£ 30,000-£ 40,000$ then one session a week would represent a cost of $£ 3,000-£ 4,000$ per year depending on the consultant's contract. It would represent a loss of 